\title{
WHITTAKER'S CORRELATION OF PHYSICS AND PHILOSOPHY
}

\author{
by JAMES McCONNELL
}

\section{Introduction}

Whittaker's studies of the relations between physics and philosophy are contained in about forty books and papers, nearly all of which were published during the last fifteen years of his life. His approach is mainly historical and is a natural sequence to his History of the Theories of Aether and Electricity. Many of the publications were based on lectures delivered to various groups and there is naturally a certain amount of repetition. To give an account of his work we divide it somewhat arbitrarily into the investigations on the topics :-
1. Neo-Cartesianism,
2. Eddington's Principle,
3. Determinism and Freewill,
4. Cosmological Theories,
5. Natural Theology.

These topics are not exhaustive, but it is hoped that they may suffice to present the chief features of Whittaker's philosophical speculations.

\section{Neo-Cartesianism}

René Descartes * was born in 1596 at a period when the mathematical and physical sciences were making rapid strides. On evaluating at the age of twenty-four the results of his study of philosophy he found himself dissatisfied with the lack of unanimity among the different schools of philosophers. On the other hand the propositions of mathematics were accepted without question by everyone who was capable of understanding them. Kepler had insisted that the chief aim of all investigations of the external world should be to discover the rational order and harmony which had been impressed on it by God and which He revealed to us in the language of mathematics; and Descartes saw that this doctrine had a wider application, that it could in fact be extended to general philosophy. The marks that should distinguish true philosophy were, he was persuaded, clarity as regards fundamental principles and incessant fertility of discovery ; and these marks he perceived in the mathematical sciences and nowhere else. Descartes therefore set himself the problem to reform philosophy by a new method framed in the likeness of mathematics ; what he sought was to exhibit all the complexities of knowledge

* For this section see The Modern Approach to Descartes' Problem (Thomas Nelson and Sons Ltd., London, 1948). Space and Spirit (Thomas Nelson and Sons, Ltd., London, 1947). History of the Theories of Aether and Electricity-The Classical Theories, Chapter I (Thomas Nelson and Sons, Ltd., London, 1951).

E.M.S. $-\mathrm{D} 3$ 
as consequences of a set of ultimate principles of extreme simplicity-innate ideas-which everyone would be willing to take for granted.

Descartes' problem is a metaphysical one but he rejected the metaphysics of the scholastics as useless for the investigation of the physical world. Instead he chose and canonised a purely mechanical investigation of nature ; "Give me matter and motion and I will construct the universe." Matter for him is characterised simply by extension; extension constitutes matter and matter constitutes space. Interplanetary space is filled with a transparent matter which serves to transmit force and light; there is no such thing as action at a distance. Another experience which is measurable is the passage of time and hence the movement of bodies admits of quantitative treatment. The inorganic world then is a closed system whose behaviour is determined strictly by mathematical laws.

The main defect in this system was that it failed to link up with anything beyond the material universe like human consciousness or the ideas of value or purpose. In fact the whole of reality cannot be represented in terms of mathematical quantities.

Whittaker proposes a neo-Cartesianism, viz., a philosophy founded on the principle that the search for a universal science should be modelled on the procedure of physicomathematicians. It must be accepted that it is allowable to draw freely on experimental results ; in later life Descartes himself realised that it was not possible to discover his innate ideas by merely examining the contents of our mind. In order to build up a theory of geometry Whittaker assumes as an axiom based on experience that a material body can change its situation without being changed in any other way. This allows us to introduce the motion of a measuring-rod and this in turn allows us to compare the size of bodies. A particle is a body whose dimensions are negligibly small compared with the measuring-rod and a point in the idealisation of a particle. In three-dimensional Euclidean geometry there is a fixed relation between the ten mutual distances of any five points, and such a relation may be verified by measurement for the ten mutual distances of five material particles. We assert that the relation between the mutual distances of actual particles are those characteristic of Euclidean geometry. This is, of course, claimed only for the departments of the physical world where General Relativity does not enter.

Whittaker then introduces the notion of reality for his neo-Cartesianism. The test of reality is value for purposes of prediction. The motion of predictability involves the notion of laws of nature, e.g., gravitation, electromagnetics, theoretical geometry ; the laws of nature form a rational structure underlying nature ; we are finally led to conclude that reality is at every point in intimate relation with this structure and that a knowledge of the structure may be used to determine fresh constituents of reality. This is illustrated by the predictions as a result of mathematical reasoning of conical refraction by Hamilton and of the bending of light rays in the sun's gravitational field by Einstein. To 
decide what entities are real we begin by dividing the experience of an individual into those elements that are peculiar to himself and those that are interobjective, i.e., common to many minds. The interobjective elements are real. Reality is also to be attributed to things which are not directly observable but which have been introduced by the principle that nature is a rational interrelated structure in order to account for observed phenomena, e.g., the wave aspect of the electron.

The mathematics involved in the tuning of musical instruments links resthetics with mathematics. The common agreement on the tuning of instruments proves that the musical æsthetic values have an integral interobjective character and are therefore real. Whittaker then states *: "Once the reality of resthetic values has been admitted, the reality of moral values can be established without much difficulty" -in contrast with the cleavage between the mechanics of the inanimate world and the idea of value in the old Cartesianism. The assertion of a rational structure of the universe and of moral values provides a foundation for natural theology.

While admiring this attempt to solve Descartes' problem one does not feel too happy about the transitions from mathematics to resthetics and from wsthetics to ethics. Art critics might not be satisfied that the tuning of instruments provides a basis for a theory of æsthetics. Besides, good and bad taste is something quite different from good and bad conduct, for it is moral obligation that distinguishes between right and wrong. If the transitions from mathematics to moral values are not firmly established, Whittaker's attempt does not succeed in remedying the defects of Descartes' solution.

\section{Eddington's Principle}

The investigations of Newton established the principle that science rests fundamentally on observation and experiment. However, the theoretical prediction of conical refraction and of the bending of light rays mentioned above, and more recently the prediction of the existence of elementary particlespositron and meson-has led scientists, notably the late Sir Arthur S. Eddington to ask the question: What is the minimum set of observational data which is sufficient to form a basis for the whole edifice of physical theory?

To understand Eddington's answer to the question $\dagger$ we must distinguish between quantitative assertions like "The velocity of light is $3 \times 10^{10} \mathrm{~cm}$. per sec." ; "The value of the reciprocal of the fine-structure constant is 137 ", and qualitative assertions like "The velocity of light is independent of the motion of its source" ; "Inside a hollow electrified shell there is no electric field." Eddington laid down the principle: All the quantitative propositions of physies, that is, the exact values of the pure numbers that are constants of

* 'The Modern Approach to Descarlos' Problem, page 29.

+ For this sertion see Some Dispuled Questions in the Philosophy of the Physical Sciences (Pror. Roy. Sor. Edinburgh, A, LXI-Part II, page 160, 1942), From Euclid to Eddington (Camb. Univ. Press, 1949), Eddinglon's Principle in the Philosophy of Science (Camb. Univ. Press, 1951). 
science, may be deduced by logical reasoning from qualitative assertions without making any use of quantitative data derived from observation. Among the qualitative assertions are included the postulates of impotence, e.g., the uncertainty principle in quantum mechanics, the impossibility of constructing a perpetual motion machine. In virtue of his principle Eddington proposed the integral value 137 for the reciprocal of the fine-structure constant. He calculated the number $\mathrm{N}$ of particles in the universe and found it equal to the number of particles in Einstein's cylindrical world, if it is supposed that the ultimate constituents of matter are protons and electrons. From $\mathbf{N}$ he deduced the ratio of the electrical to the gravitational forces between two electrons. He also established a quadratic equation which gave the electron and proton masses to a high degree of accuracy.

Whittaker is clearly in admiration of the successes of Eddington's predictions but is in disagreement with his claim that the fundamental laws and constants of physics are wholly subjective. Thus the postulates of impotence, which play a large part in Eddington's theory, are convictions which have been formed as a result of countless experiments. Then with regard to the fruits of the theory the only new information is the value of $N$. That this should be taken as the actual number of particles in the universe could scarcely be accepted nowadays when Einstein's cylindrical model is out of favour and when so many elementary particles apart from the proton and electron have been discovered.

Those who have listened to Eddington expounding his theories may recall a feeling of frustration at hearing the lecturer speak in an unintelligible language about matters of fundamental importance in physics. It is possible that Eddington's work would have been ignored had not Whittaker focused attention on it. For this and for pointing out the epistemological defects he has placed both philosophers and mathematical physicists under a debt.

\section{Determinism and Freewill}

Freewill poses to metaphysicians the question: If God knows what we shall do in the future, how can we be said to act freely? The problem of freewill has also engaged the attention of both classical and quantum physicists and a searching analysis of the problem was given by Whittaker in the twentyseventh Guthrie lecture * entitled Chance, Freewill and Necessity in the Scientific Conception of the Universe.

Science may be defined as the attempt to understand the world by tracing the connexion of events with each other ; and this is effected by ordering our experiences according to the category of cause and effect, discovering for every phenomenon its determining agents or antecedents. The affirmation that this connexion is all-embracing, that no event happens without a cause, constitutes the postulate of causality. This has been stated by Kant as :

* Proc. Phys. Soc., 55, 459 (1943). 
"All changes take place according to the law of the connexion of cause and effect." For him the postulate is an a priori epistemological axiom independent of experience, and is a necessary presupposition for natural science. Moreover, Kant tacitly restricts "cause" to mean "an antecedent phenomenon of a purely physical character". In other words, the cause of physical phenomena is to be found in the physical world-physics is a closed system, and the same antecedent phenomena lead to the same effect-physics is deterministic.

The advent of quantum mechanics, and in particular the uncertainty relation, has compelled scientists and philosophers to recast some of the notions about cause and effect which were previously regarded as axiomatic. However, before entering into philosophical questions raised by the new physics, let us with Whittaker consider in more detail the problem of causality as it existed in classical mechanics. If a coin is tossed in the air, we cannot say on which side it will fall. The reason for this is that we do not know the initial translational and rotational velocities, the exact shape of the coin, or the law of air resistance. If all such factors, which we shall call hidden parameters, were known, then it would in principle be possible to determine precisely the motion of the coin. The tossing of the coin is called by Whittaker crypto-deterministic, which signifies that the motion is deterministic but that it cannot be predicted on account of our lack of information regarding the hidden parameters. A gas may be considered in terms of molar variables like pressure, temperature, density and in terms of corpuscular variables like the position and velocity of a single molecule. The molar variables are deterministic and the corpuscular variables are crypto-deterministic. In classical theory anything which appears to occur by chance is actually crypto-deterministic.

In quantum theory the diffraction of electrons by a crystal, the passage of a plane-polarised light say through a Nicol prism, and radioactivity exhibit features which are certainly not deterministic. Nor indeed are they cryptodeterministic. This may be most clearly seen in the experiment with the Nicol prism. A fraction $\cos ^{2} \phi$ of the intensity is transmitted while $\sin ^{2} \phi$ is reflected, where $\phi$ is the angle between the planes of polarisation of the incident and emergent beams. If the history of any photon depends on a hidden parameter, then before meeting the prism $\cos ^{2} \phi$ of the photons must have one value of the parameter and the remainder must all have another value. However, initially, the photons have no relation to the angle $\phi$, so the hypothesis of hidden parameters fails and the fate of the individual photons is simply indeterminate.

Turning to the philosophical problem Whittaker distinguishes between the physical and the psychological aspects of causality. In the physical aspect the principle of causality is just the assertion that all phenomena are completely determined by antecedent phenomena. To deal with the psychological aspect he distinguishes with the scholastics between the appetitus sensitivus, the desire for some particular object, and the appetitus rationalis, the desire of an object only in so far as it leads to the fulfilment of an ideal, 
e.g. conformity to the moral law. Those who assert that moral decisions are governed by physical determinism ignore the fact that the appetitus sensitivus and appetitus rationalis are linked to the personality in entirely different ways, and that it is this difference of linkage which is the source of freedom of the will ; for example, a man can feel a strong desire to take money and at the same time revolt against the idea of stealing. This duplication of the personality into the objective, which contains the phenomena under consideration, and the subjective, which apprehends and deals with them, bears no resemblance whatever to mechanical forces acting at a point.

So determinism must be rejected both in the physical and in the moral spheres. The universe is not just a mathematical consequence of the disposition of the particles at the Creation, and is a much more interesting and eventful place than any determinist imagines.

At the end of the lecture Whittaker just mentions the problem of how God's foreknowledge can be reconciled with man's freewill, and perhaps it may not be out of place to give briefly the scholastics' solution of the problem.* God is eternal and things which are past, present or future to us are all present to Him. Just as we at this moment can witness free acts, so God can see free acts which relative to us are in the future.

\section{Cosmological Theories}

Throughout his life Whittaker maintained a keen interest in theology and in a number of his writings he studies the possible repercussions that recent developments in physical theories may have on theological questions. In a review $\dagger$ of Scientific Theory and Religion by $\mathrm{E}$. W. Barnes he even suggests that, for the future, mathematicians may be the religious teachers of the many who have drifted away from revealed religion. The work of Whittaker in this field has given rise to much discussion, so it is worthwhile to state the position which he assumes. $\ddagger$

The contact of religion with the physical sciences is as yet imperfect because their domains of interest are different. The physicist is concerned with occurrences in space and time which are capable of being repeated and therefore can be made the subject of prediction. These lead to laws of nature like Newton's law of gravitation or the law of conservation of energy. If we confine ourselves to classical mechanics, such laws are invariable and the universe is a closed system. We can then study it without introducing theology.

Many things of importance, like freewill and moral responsibility, are outside the scope of scientific investigation, and even in the physical world any occurrence which is unique and therefore cannot be repeated takes us outside the province of science. Examples of this are the beginning and the end of the world. "As will be shown, when by purely scientific methods we trace the

* C.f. St Thomas Aquinas, Summa Theologica, I, q. 14, a. 13.

† Dublin Revieu, 97th year, page 286 (1933).

$\ddagger$ See especially The Beginning and End of the World (Oxford Univ. Press, 1942). 
development of the material universe backwards in time, we arrive ultimately at a critical state beyond which the laws of nature, as we know them, cannot have operated : a Creation, in fact. Physics and astronomy can lead us through the past to the beginning of things, and show that there must have been a Creation: but of the Creation itself, science can give no account."* The birth and extinction of the universe can be understood only by bringing into consideration those aspects of reality which are ignored by science and interpreted by religion alone.

Science cannot affect the dogmatic teaching of Christianity but it can have an apologetic value. In fact the outlook of a civilised man is to a certain extent formed by the scientific methods and philosophy of his time, and these may have a psychological value in disposing his mind towards belief or disbelief. For example, he may contrast the agreement on propositions in mathematics and physics with the discord among theologians of various sects and may conclude that religion is inferior to science in its mode of demonstration. However, in arriving at such a conclusion, he would forget that the certitude of science is reached only because it is confined to logical inferences from observation to experiment, whereas the conviction of religious truth involves a combination of both the intellect and the will, and in this field agreement is not to be expected. Religion is not thereby a matter of personal opinion and the steadfastness with which Christianity has held to its fundamental dogmas for nearly two thousand years is in sharp contrast with the changing beliefs in scientific theories.

Having stated Whittaker's position let us examine with him a few special questions abbreviating his excellent historical accounts. In the nineteenth century it was assumed that matter and energy had been proved by science to be eternal, and from this German philosophers argued that life and mind are merely forms of matter and energy. This assumption is shown to be false by the findings of modern physics. Nowadays we have very many ultimate constituents of matter-the electron, positron, proton, negative proton, neutron, antineutron, neutrino and several types of meson-and not one of these is indestructible. Moreover we cannot picture these ultimate constituents as bodies with a finite extension, position, velocity, etc.; they have both a wave and a particle aspect. Thus the external world is constituted of entities which have no permanent existence, no shape, no location and which cannot be described otherwise than by mathematical formulæ : by aid of these formulæ the result of any experiment can be predicted: and this prediction is the sole function and capability of science. Thus mechanism has been replaced by a pan-mathematical conception of the universe and there is no scientific basis whatever for nineteenth-century materialism.

In discussing the above question Whittaker recalls a distinction made by the scholastics which is very useful in dealing with mechanical models. Already in the second century B.C. Hipparchus described the motion of the sun relative

\footnotetext{
* The Beginning and End of the World, page 4.
} 
to the earth in two ways : firstly, as a circular motion with the earth not quite at the centre; secondly, as a circular motion with the centre of the circle describing a circle about the earth as centre. Both were adequate to account for the observed phenomena and to make predictions, and they were said to save appearances-salvare apparentias. It could not, however, be claimed that either hypothesis was actually verified in nature-in esse et secundum rem. The question as to which class does a theory belong has, with the advent of relativity and quantum theory, ceased to have a meaning. In macroscopic physics there is no justification for saying that light consists of undulations because with the collapse of the rether theory there is nothing to undulate. Besides, models formed from ordinary gross matter cannot account for the dual wave-particle aspect of the entities discussed in atomic physics.

We now consider Whittaker's treatment of cosmology, by which term we shall understand the physics of the universe as a whole. Most of the Greek philosophers believed the heavenly bodies to be alive, divine and incorruptible, knowing no change other than circular and uniform motions, and governing the affairs of men. These ideas could not be accepted by Christians and the repudiation of Hellenic cosmologies may be regarded as the starting point of modern science.

The development of the universe may be studied in the light of thermodynamics or of astronomy, or indeed by a combination of both as in the theory of the primeval atom.* It is shown in thermodynamics that entropy, which is a measure of the disorder of a system, cannot decrease. This is called the degradation of energy. The total amount of energy in the universe does not change but it is always suffering degradation. The universe is running down and will eventually attain its state of maximum entropy, when all bodies will be at the same temperature and life will have ended. "Since entropy is essentially positive, its steady increase must have had a beginning-a creation, when the total entropy of the universe was less than it has ever been subsequently. It was never possible to oppose seriously the dogma of the Creation except by maintaining that the world has existed from all eternity in more or less its present state : and no one can now hold this language in face of the facts." $\dagger$

These considerations provide no idea of the age of the universe, but this is given in several ways by astronomy. Theories of the generation and radiation of stellar energy indicate that the life of a typical star is between $10^{10}$ and $10^{11}$ years. The stability of star-clusters shows that they would be disrupted after about $10^{10}$ years, and allowing for the effects of the accretion of matter from the cosmical cloud we arrive at an estimate of about $5 \times 10^{10}$ years for the age of the galaxy. The recession of the extra-galactic nebulæ implies that all matter must have been crowded together in a comparatively small region about $2 \times 10^{9}$ years ago. Since the calculations involved in all these estimates

* G. Lemaître, The Primeval Atom (Van Nostrand, New York, 1950).

$\dagger$ The Beginning and End of the World, page 40. 
are very approximate, the results are mutually compatible and there is this good evidence for a crisis happening about $10^{9}$ or $10^{10}$ years ago, in which the nebulæ, the stars, and even the earth, originated almost simultaneously. "There is no ground for supposing that matter (or energy, which is the same as matter) existed before this in an inert condition, and was in some way galvanised into activity at a certain instant : for what could have determined this instant rather than all the other instants of past eternity? It is simpler to postulate a creation ex nihilo, an operation of the Divine Will to constitute Nature from nothingness." *

Before trying to assess the value of Whittaker's discussion of the question of the Creation let us recall what is known of it from philosophy and revelation. The word creation is understood by philosophers to mean the production of a thing out of nothing-productio rei ex nihilo. It means something very different from, for example, the creation of electron pairs in atomic physics which is really nothing more than the transformation of gamma rays into electrons and positrons. The fact of Creation is established mainly by the first verse of Genesis : "In the beginning God created heaven and earth ", and by the first three verses of St John's Gospel: "In the beginning was the Word, and the Word was with God, and the Word was God. The same was in the beginning with God. All things were made by Him ; and without Him was made nothing that was made." The exegesis of these texts shows that God, and God alone, made the world out of nothing, i.e. created the world, in the beginning of time. From the philosophical viewpoint the scholastics showed that Creation is something possible though the notion of it is difficult for us to grasp. $\dagger$ A much discussed question was whether the Creation in time, established by revelation, could be established also by philosophical arguments. The weight of opinion is against such an assertion; in other words, it cannot be shown by metaphysical arguments that the age of the world is finite. $\ddagger$

Let us now go back to the first quotation of the present section. It seems that Whittaker employs the word "Creation" here to designate merely the event which marked the beginning of the operation of the laws of nature without asserting that this event was a productio ex nihilo. This is confirmed by the second quotation where it identifies "creation" with the beginning of the increase of entropy. It is perhaps a little confusing that a few lines later he speaks of "the dogma of the Creation", in which it is implied that the idea of creation is understood in the philosophical sense. However, he does make the point that by the argument from the degradation of energy the laws of physics could not have operated from all eternity. In the argument from astronomy he opposes the view that matter existed in an inert state from all eternity and was at some instant galvanised into activity: "for what could

* Ibid., page 63 .

$\dagger$ Cf. St Thomas Aquinas, Summa Theologia, I, q. 44-46 De Potentia, q. 3, a. 5.

$\ddagger$ Cf. St Thomas Aquinas, De Aeternitate Mundi contra Murmurantes. 
have determined this instant rather than all the other instants of past eternity?" The Divine Will, of course, which is completely free in its operations with regard to created things.

While the findings of modern science have not established the fact of creation in time, and of this Whittaker was aware, their apologetic value is considerable. Let us again quote from Whittaker *:

"These different estimates converge to the conclusion that there was an epoch about $10^{9}$ or $10^{10}$ years ago, on the further side of which the cosmos, if it existed at all, existed in some form totally unlike anything known to us: so that it represents the ultimate limit of science. We may perhaps without impropriety refer to it as the Creation. It supplies a concordant background to the view of the world which is suggested by the geological evidence, that every organism ever existent on the earth has had a beginning in time. If this result should be confirmed by later researches, it may well come to be regarded as the momentous discovery of the age; for it represents a fundamental change in the scientific conception of the universe, such as was effected four centuries ago by the work of Copernicus."

\section{Natural Theology}

The most controverted of Whittaker's publications is Space and Spirit, which deals with the possible repercussions of the results of modern scientific investigation on the traditional proofs from reason of the existence of God. These proofs go back to the ancient Greeks and are synthesised in the Five Ways of St Thomas Aquinas which briefly run as follows $\dagger$ :

1. The first way is from motion. It is known from experience that things are moved. Anything that is moved, is moved by another. We cannot have an infinite sequence of movers and moved, because we would then have no first mover and therefore no other mover. We must thus arrive at a first mover, which is not moved by another, and this first mover is God.

2. The second way is from causality. We find in nature an order of efficient causes and it is not possible that anything should be the cause of itself. We cannot have an infinite sequence of causes because, if we had no first cause, there would be no subsequent cause or effect. So there is a first efficient cause, which is God.

3. The third way is from contingent being. We find in the world things which are contingent, i.e. which may or may not exist. It is impossible that all such things always existed because what need not exist sometimes does not exist. Not all things are contingent; some must be necessary, and as before we arrive at an uncaused necessary being, which is God.

4. The fourth way is from grades of perfection. We find different grades of good, noble, etc. in the world and these grades are distinguished by their

* Space and Spirit, page 118.

† St Thomas Aquinas, Summa Theologica, I, q. 2, a. 3. 
deficiency from a being that is supremely good, noble, etc. This being, which must be the cause of the perfections in created things, is God.

5. The fifth way is from order. Natural bodies devoid of reason are found to act for a purpose. There must therefore exist a being endowed with reason that directs the natural bodies, and this being is God.

To discuss Whittaker's treatment of St Thomas' proofs we may take the first two ways together; they are metaphysically equivalent to each other. Whittaker observes that a chain of causes can be closed, and that for the proofs to be valid it is necessary that the relation of moved to mover or of effect to cause be monotonic, that is to say, that it be connected with entities that always increase or always decrease. St Thomas did take care of this point, as is shown by a quotation from his Compendium Theologiae. In terms of modern physics we can say that the cause and effect relation is monotonic because no physical influence can be transmitted at a speed greater than $c$ and therefore cause precedes effect in time. The sequence of causes cannot go back to infinity but must end at the "Creation". At this point we arrive at the first cause wheh is outside the world, viz. God.

The argument from contingent being is reinforced by the conclusion of modern science that all matter is destructible.* Moreover the absence of determinism and of crypto-determinism in quantum mechanics suggests that there is a continual succession of divine intrusions. In other words, the deistic theory that at the Creation God set the world going and then left it to itself gives way to the divine conservation of the world-the conservare in esserequired both by revelation and metaphysics.

The fourth way is not examined in detail by Whittaker because it is not very closely related to the external material world. On the other hand he treats of the fifth way at some length. The statement that natural bodies act for a purpose is not very intelligible to the twentieth-century mind; it could be better expressed by saying that the behaviour of natural bodies, at least in their molar aspect, is governed by the laws of mathematical physics. From the existence of mathematical law one can infer that there exists a mind analogous to our mind that established this order. Moreover the same laws are valid all over the universe, so we argue to a single mind directing the whole cosmos, thus excluding polytheism. Furthermore since by the argument from the degradation of energy life will cease to exist at some time in the universe, we cannot identify God with the world and so we must reject pantheism.

The chief merit of Whittaker's arguments is the light which they throw on the fundamental properties of created things, viz. that they are subject to change, that there cannot be an infinite sequence of causes, that there is order in the world. A study of physics alone will not link the material world to the infinitely intelligent, necessary First Cause. Nevertheless an honest thinker cannot fail to look outside the material world for an answer to the

* The Beginning and End of the World, page 24. 
questions of the origin and the purpose of his own existence. It was such a person that Whittaker had in mind when writing Space and Spirit, and he has done a good service to philosophy by examining how modern physical theories may lead up to the traditional proofs of God's existence.

\section{Conclusion}

The picture that one forms of Whittaker from his philosophical writings is that of the scholarly Christian layman-one cannot help comparing him with Sir Thomas More-whose scholarship brought him to a better appreciation of fundamental truths. He deplores that in modern life " the sense of creatureliness and dependence has passed away, and God is left out of account" * realising that the human personality is perfected by conforming one's will to the immutable Divine Will.

In correlating physics and metaphysics Whittaker is in the happy position of the thirteenth-century disciples of St Albert the Great and St Thomas Aquinas, who both placed philosophy and science side-by-side within the domain of free reason. $\dagger$ Nowadays when the dangers of over-specialisation are feared, it is perhaps not inopportune to suggest that philosophy could profitably have a place in the university courses for science students. As Whittaker points out, $\ddagger$ the line of descent of the modern physicist is to be traced not from the humanists of the Renaissance, but from the scholastics of the twelfth and thirteenth centuries who translated into Latin the Arabic version of Greek mathematics and science. The divorce of science and philosophy has now resulted in the unfortunate situation that the number of competent physicists who are also competent metaphysicians is infinitesimally small. The union of the two studies would undoubtedly be of benfit to both, and those who in the future will work for that union will be inspired by the valuable investigations of Edmund Taylor Whittaker.

I am indebted to Professor J. D. Bastable for helpful advice, and to Professor P. J. McLaughlin for making available to me his correspondence with Sir E. T. Whittaker.

* The Beginning and End of the World, page 41 .

$\dagger$ Space and Spirit, page $\mathbf{2 6}$.

$\ddagger$ Ibid., page 135 .

St Patrick's College

MaYNoOTH

IRELAND 